\title{
Dimensions of Employee Deviance among Emergency Services Personnel in Malaysia
}

\author{
Muhammad Madi Bin Abdullah ${ }^{1}$ and Leong Weng, Lee ${ }^{2}$ \\ ${ }^{1}$ University College of Technology Sarawak, Sibu, Sarawak, Malaysia \\ ${ }^{2}$ Asia eUniversity, Malaysia.
}

\begin{abstract}
Employee deviance represents a costly behavior to many organizations. The present study attempts to analyze dimensionality of employee deviance among emergency services personnel in Malaysia. A survey was conducted, with 201 respondents. Descriptive statistical analysis indicated that said something hurtful to someone at work, cursed at someone at work, made fun of someone at work, played a mean prank on someone at work and spent too much time fantasizing and daydreaming are discovered as the most common forms of interpersonal deviance. While taken an additional or longer break than is acceptable at your workplace, come in late to work without permission, intentionally worked slower than you have worked showed and littered your work environment are the most common forms of organizational deviance. This research has highlighted the common forms of employee deviance engaged by the respondents of this study.
\end{abstract}

Key words: Employee Deviance, Emergency Services, Interpersonal deviance, Organizational deviance

\section{INTRODUCTION}

For the past four decades, the study of employee behavior in organizations has remained an imperative part of human resource management. Many scholars have examined positive work behaviors such as organizational citizenship behaviors [1], [2], work engagement [3], [4] and work commitment [5], [6] while limited studies have examined the negative work behaviors such as employee deviance. The subject of employee deviance has received limited attention albeit deviant behaviors are generally destructive and hurtful to the well-being of an organization [7]-[10]. Besides, employee deviance is an issue that has impinged upon most organizations, employers, human resource managers, academics and practitioners because employee may exhibits in various acts with the organizations [11].

[12] have identified employee deviance as a single construct, whereas few studies have focused on the specific deviant acts engaged by employees [11], [13], [14]. Moreover, each deviant act cannot be equated since that deviant behaviors ranges from minor deviant act, for instance leaving early among employees, to serious act such as sabotaging equipment that have resulted in organizational losses [15], [16].
[13] in their typology of employee deviance have categorized employee deviance into four quadrants which later became a basis to study its dimensionality [11]. Although most of the dominant deviant behaviors were covered, still the applicability of employee deviance framework in emergency services centers is not well established in literature. Similarly, the subject of employee deviance has traditionally been studied from the perspective of developed countries like America [10], [17], [18] and used administrative employees [19], [20], and part-time students [21] as samples. Thus, employee deviant behavior in western countries may not be a deviant behavior in Asian countries [22], [23]. Moreover, findings from administrative employees or part time students may not have similar implications for employees in emergency services. Therefore, this study will attempt to analyze dimensionality of employee deviance in emergency services centers of Malaysia to contribute to the gap in existing employee deviance literature.

\section{DIMENSIONS OF EMPLOYEE DEVIANCE}

There are many labels of employee deviance. [24] have defined employee deviance as a voluntary behavior that violates significant organizational

Corresponding Author: Muhammad Madi Bin Abdullah, University College of Technology Sarawak, Sibu, Sarawak, Malaysia 
norms and, in doing so, threatens the well-being of an organization, its members or both. Examples of employee deviance behaviors include production deviance, gossiping about co-workers, theft, sabotaging equipment, and personal aggression. They have categorized employee deviance into two dimensions (see Figure 1), namely interpersonal and organizational deviance [13] and they postulated that the antecedents to each type of employee deviance are different [13], [19], [25]. Hence, an investigation of acts which are considered as employee deviance are beneficial to organizations to formulate preventive policies and practices that would be able to hinder employee deviance. These preventive policies and practices will be in return enhance employee productivity and improve organizational effectiveness.
As of now, there are several measures of employee deviance. The most widely used scales is Robinson and Bennett's (1995) Workplace Deviant Behavior Scale. There are 17 items to measure the two dimensions of employee deviance: 7-item and 12items to measure interpersonal and organizational deviance respectively. This scale had demonstrated a good internal consistency and test-retest reliability [15], [26]. In addition, [24] advised that the total score can be used in empirical research since there is moderate correlations between the two dimensions. Besides, the workplace deviant behavior scale demonstrated acceptable psychometric properties in organizational studies [13], [24].

Figure 1: Typology of Employee Deviance (Robinson and Bennett, [13])

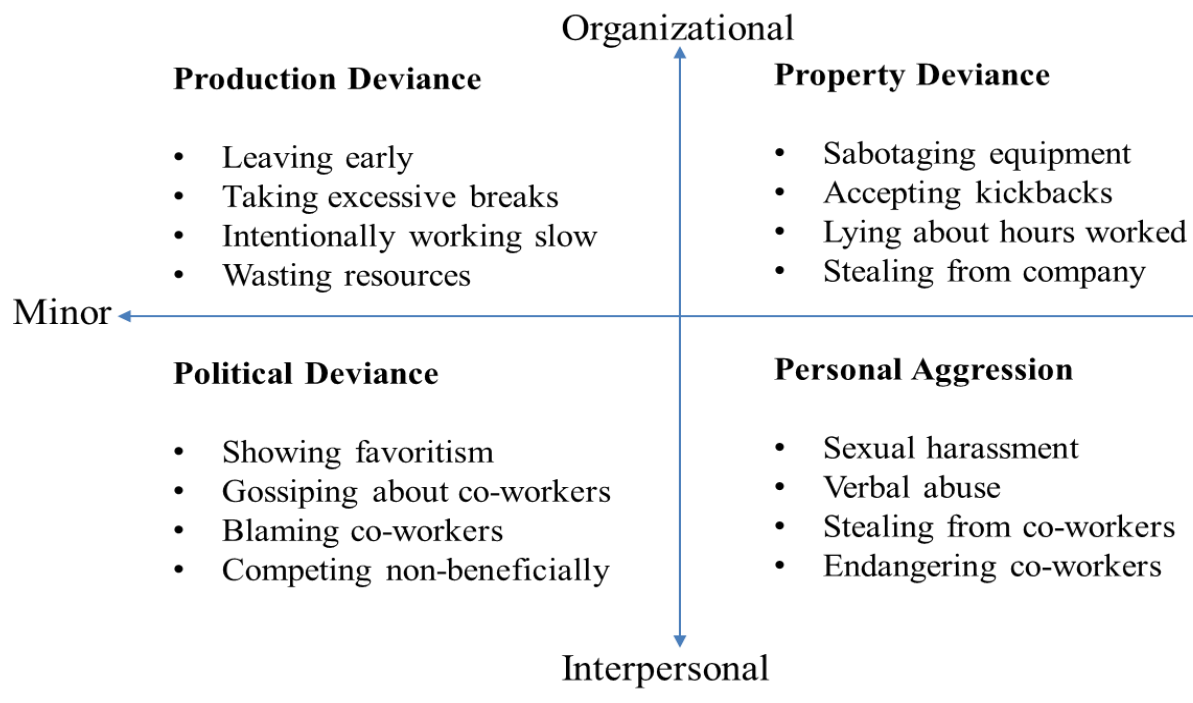

\section{METHODOLOGY}

\section{Sample}

Employees working in emergency services centers were surveyed. The identity of surveyed centers is not disclosed to ensure anonymity and also, due to the nature of questions about employee deviant behaviors. Data collection activity was collected by the authors using a questionnaire, and it took placed between May to September 2018. Table 1 summarizes the demographic characteristics of the study respondents.

In total of 209 respondents, $55.5 \%$ respondents were male while $44.5 \%$ were female. The sex composition represents population in emergency services centers of Malaysia and it was normal. Most of the emergency services and rescue works required physical strength, and also generally men are stronger than their female colleagues. Next, majority of the respondents $(69.4 \%)$ were single, while $30.6 \%$ were married. In reference to highest level of education attained, more than half $(50.7 \%)$ completed high schools, $38.3 \%, 9.6 \%$ and $1.4 \%$ respondents completed certificate/ diploma, undergraduate and postgraduate degrees respectively. The age group of respondents in this study is relatively young, mean 25.4 years old and with a standard deviation of 5.6. Besides, the mean and standard deviation of job tenure is 3.5 years and 3.3 respectively. The composition of respondents with reference to demographic characteristics is quite diverse and it represents the population of employees working in the emergency services centers in Malaysia.

\section{Questionnaire}

The questionnaire was adopted from [24]. Respondents of this study were required to respond on three-point categorical scale, with 1 representing never, 2 representing sometimes and 3 representing 
frequently about various employee deviant behaviors which they engaged at their workplace. A total of 400 questionnaires were distributed to selected emergency services centers in Malaysia. All respondents were assured of anonymity; an envelope was given to all respondents. All respondents were asked to place their questionnaire inside the envelope and seal it using the envelope given. Then, they need to return their questionnaire either to the researchers directly or into sealed boxes placed in offices of the selected emergency centers. This is to protect their confidentiality and anonymity as well as the sensitive nature of the questions asked in the questionnaire which subject to social biasness. 241 questionnaires were received, and 32 incomplete questionnaires were removed. As a result, the respond rate of this study was $52.3 \%$ with 209 useable responses.

Table 2 summarizes various employee deviant behaviors that exist in emergency services centers in Malaysia. It also highlighted some prevalent deviant acts committed by their employees. In general, descriptive analysis showed existence of employee deviant behaviors among respondents and in diverse forms, as well as their regularity rate.

Table 1: Demographic characteristics $(n=209)$

\begin{tabular}{|c|c|c|c|c|}
\hline & Frequency & Percentage & Mean & SD \\
\hline Age (years) & & & 25.4 & 5.6 \\
\hline $18-22$ & 88 & 42.1 & & \\
\hline $23-27$ & 52 & 24.9 & & \\
\hline $28-32$ & 42 & 20.1 & & \\
\hline $33-37$ & 19 & 9.1 & & \\
\hline 38 and above & 8 & 3.8 & & \\
\hline \multicolumn{5}{|l|}{ Sex } \\
\hline Male & 116 & 55.5 & & \\
\hline Female & 93 & 44.5 & & \\
\hline \multicolumn{5}{|l|}{ Marital Status } \\
\hline Single & 145 & 69.4 & & \\
\hline Married & 64 & 30.6 & & \\
\hline \multicolumn{5}{|l|}{ Highest Education Qualification } \\
\hline High school & 106 & 50.7 & & \\
\hline Certificate/ Diploma & 80 & 38.3 & & \\
\hline Undergraduate & 20 & 9.6 & & \\
\hline Postgraduate & 3 & 1.4 & & \\
\hline Job tenure & & & 3.5 & 3.3 \\
\hline Below 2 years & 80 & 38.3 & & \\
\hline 2 to 6 years & 94 & 45.0 & & \\
\hline 7 years and above & 35 & 16.7 & & \\
\hline
\end{tabular}

Table 2: Percentage reported of the dimensions of employee deviance

\begin{tabular}{llccc}
\hline Item & & Never & Sometimes & Frequently \\
\hline \multicolumn{2}{l}{ Interpersonal deviance } & & & \\
1 & Made fun of someone at work & 35.4 & 46.4 & 18.2 \\
2 & Said something hurtful to someone at work & 30.1 & 60.8 & 9.1 \\
3 & Made an ethnic, religious or racial remark at work & 67.5 & 27.8 & 4.8 \\
4 & Cursed at someone at work & 32.1 & 54.5 & 13.4 \\
5 & Played a mean prank on someone at work & 39.7 & 56.5 & 3.8 \\
6 & Acted rudely toward someone at work & 55.5 & 39.7 & 4.8 \\
7 & Publicly embarrassed someone at work & 65.6 & 32.1 & 2.4 \\
8 & Taken property from work without permission & 62.2 & 34.9 & 2.9 \\
9 & Spent too much time fantasizing or daydreaming & 42.6 & 53.1 & 4.3
\end{tabular}




\begin{tabular}{lllll}
\multicolumn{2}{l}{ Organizational deviance } & & & \\
10 & Falsified a receipt to get reimbursed for more money than you spent & 76.1 & 22.5 & 1.4 \\
11 & Taken an additional or longer break than is acceptable at your workplace & 34.4 & 56.0 & 9.6 \\
12 & Come in late to work without permission & 38.3 & 55.5 & 6.2 \\
13 & Littered your work environment & 45.9 & 48.8 & 5.3 \\
14 & Neglected to follow your officer instruction & 55.0 & 40.7 & 4.3 \\
15 & Intentionally worked slower than you could have worked & 38.3 & 54.5 & 7.2 \\
16 & Discussed confidential information with an unauthorized person & 53.6 & 40.2 & 6.2 \\
17 & Used an illegal drug or consumed alcohol on the job & 92.3 & 6.7 & 1.0 \\
18 & Put little effort into your work & 57.9 & 40.2 & 1.9 \\
19 & Dragged out work in order to get overtime & 63.6 & 35.4 & 1.0 \\
\hline
\end{tabular}

\section{RESULT ANALYSES AND DISCUSSIONS}

This present study is possibly the primary attempt in Malaysia to segregate various forms of employee deviant behaviors in emergency services centers. Though that there is a general perception about emergency services of being stressful and traumatic [27]-[29], however its coping behaviors remained vague. This study will contribute to the understanding of employee deviance and the dynamics of emergency services employees in Malaysia. Despite the fact that this study examined the employee deviant behaviors in emergency services setting in Malaysia, still logically the findings of employee deviance will be still be applicable in other industries and countries.

Said something hurtful to someone at work appears to be the most common forms of employee deviance at interpersonal level that occurs in emergency services centers in Malaysia which only $30.1 \%$ of respondents never engaged in such deviant behavior. Other interpersonal deviant acts that showed moderate and high frequency were cursed at someone at work $(67.9 \%)$, made fun of someone at work $(64.6 \%)$, played a mean prank on someone at work $(60.3 \%)$ and spent too much time fantasizing and daydreaming $(57.4 \%)$. An interesting finding observed was $67.5 \%$ of the respondents never made an ethnic, religious or racial remark at work. One plausible explanation to this finding is probably Malaysia is a multi-ethnic, multicultural, multireligion and multilingual society, therefore majority of the employees understood the concept of respect for others.

At organizational level, taken an additional or longer break than is acceptable at your workplace give the impression of most common forms of organizational deviance. Only $34.4 \%$ of respondents never take excessive breaks while $56 \%$ involved sometimes in taking excessive breaks and $9.6 \%$ on frequently basis. Equivalently, respondents also demonstrated moderate and high frequency of come in late to work without permission $(61.7 \%)$, intentionally worked slower than you have worked showed $(61.7 \%)$, and littered your work environment $(54.1 \%)$. This finding reflects level of organizational deviance among the respondents, specifically production deviance is generally in-practice. Indebted to respondents of this study, $92.3 \%$ never used an illegal drug or consumer alcohol on the job. Habitually, employees of emergency services aware the importance of their duties and responsibilities which is to helps people during the time of needs, and cope with the emergency situations. Collectively, they take their job seriously.

[30] and [31] proposed to examine employee deviant behaviors thoroughly. [13] have emphasized on the need to study workplace deviance systematically to categorize various acts of employee deviance. This study deliberates on the prevalence deviant behaviors and confirmed the established dimensions postulated by [24]. Acts in employee deviance are interpreted differently in a diverse setting whether in different regions, countries, industries and communities. The findings of this study showed that employees of emergency services in Malaysia did engaged in deviant behaviors, still they appreciate their current job, and upholds their duties and responsibilities. It is necessary to take their feelings, concerns and agitations into considerations when studying employee deviance in different settings.

\section{CONCLUSIONS AND LIMITATIONS}

This study offers an understanding of employee deviance in emergency services in a Malaysian contaxt and helps to explain some reasons to why certain employees engaged in positive or negative behaviors at workplace. The prevalence of interpersonal deviance such as said something hurtful to someone at work and organizational deviance for instance taken an additional or longer break than is acceptable at your workplace have highlights the need to have prevention mechanism. If not, these behaviors will continuously threatens 
the well-being, productivity and operational efficiency of the organization and its member.

One of the limitations of this study is that because of the difficulty to collect data from respondents working in emergency services centers. They have very hectic schedules and unpredictable work timing as emergency calls arrive anytime of the day. Hence, there can be no generalization of results even for other emergency services centers in Malaysia, not can the results be generalized to all emergency services personnel - first responders, administrative officers, team leaders and center supervisor. The strength of this study lies in the voluntary participation of emergency services personnel in this study, therefore it is assumed that the given responses reflected the actual involvement in employee deviant behavior. More comprehensive studies can be conducted to evaluate the prevalence of employee deviance among other emergency services departments such as polices, fire-fighters, marine enforcement officers, paramilitary operation officers and hospital professionals. In addition, future studies may identify potential predictors of employee deviance, and assessing the relationship between potential predictors and employee deviance. A broader sample might reveal differences among different emergency services agencies and emergency services personnel in the country. Lastly, this study used self-reported measures of employee deviance rather an actual demonstration. Even though all questionnaires were distributed with a cover-letter assuring anonymity and voluntary participation, respondents might be more likely to give socially desirable answers. Nevertheless, [32] and [11] reaffirmed that anonymous self-reports are still able to provide the closest available proximity to the real situation.

\section{REFERENCES}

[1] R. S. Dalal, "A meta-analysis of the relationship between organizational citizenship behavior and counterproductive work behavior.," J. Appl. Psychol., vol. 90, no. 6, pp. 1241-1255, 2005.

[2] K. Lee and N. J. Allen, "Organizational citizenship behavior and workplace deviance: the role of affect and cognitions.," J. Appl. Psychol., vol. 87, no. 1, pp. 131-142, 2002.

[3] P. Kanten and M. Yesiltas, "The Effects of Positive and Negative Perfectionism on Work Engagement, Psychological Well-being and Emotional Exhaustion," Procedia Econ. Financ., vol. 23, no. October 2014, pp. 1367$1375,2015$.

[4] I. A. Hussain, N. H. Yunus, N. A. Ishak, and N. Daud, "Effects of Dimensions in Organizational Justice towards Employee Engagement," in International Conference on
Management, Economics and Finance (ICMEF 2012), 2012, no. October, pp. 169182.

[5] D. Chênevert, G. Jourdain, N. Cole, and B. Banville, "The role of organisational justice, burnout and commitment in the understanding of absenteeism in the Canadian healthcare sector.," J. Health Organ. Manag., vol. 27, no. 3, pp. 350-67, 2013.

[6] J. Lee and R. Peccei, "Perceived organizational support and affective commitment: the mediating role self-esteem in the of organization-based context of job insecurity," J. Organ. Behav., vol. 28, no. 6, pp. 661-685, 2014.

[7] I. N. 'Ain M. F. Kozako, S. Z. Safin, and A. R. A. Rahim, "The Relationship of Big Five Personality Traits on Counterproductive Work Behaviour among Hotel Employees: An Exploratory Study," Procedia Econ. Financ., vol. 7, no. Icebr, pp. 181-187, 2013.

[8] T. Levy and A. Tziner, "When destructive deviance in the workplace becomes a liability: A decisional behavioral model," Qual. Quant., vol. 45, pp. 233-239, 2011.

[9] J. Ménard, L. Brunet, A. Savoie, A. van Daele, and A. Flament, "Crossnational deviance in the workplace: Diverging impact of organizational commitment in Canada and Belgium," Eur. J. Work Organ. Psychol., vol. 20, no. 2, pp. 266284, 2011.

[10] K. Aquino, M. U. Lewis, and M. Bradfield, "Justice constructs, negative affectivity, and employee deviance: A proposed model and empirical," J. Organ. Behav., vol. 20, no. January 1998, pp. 1073-1091, 1999.

[11] S. Bashir, M. Nasir, S. Qayyum, and A. Bashir, "Dimensionality of Counterproductive Work Behaviors in Public Sector Organizations of Pakistan," Public Organ. Rev., vol. 12, pp. 357-366, 2012.

[12] M. N. Aizzat, N. H. Ahmad, and A. A. Razalli, "Politics, Justice, Stress, and Deviant Behaviour in Organizations:," Int. J. Bus. Soc., vol. 15, no. 2, pp. 235-254, 2014.

[13] S. L. Robinson and R. J. Bennett, “A Typology of Deviant Workplace Behaviors: a Multidimensional Scaling Study.," Acad. Manag. J., vol. 38, no. 2, pp. 555-572, 1995.

[14] M. L. Gruys and P. R. Sackett, "Investigating the Dimensionality of Counterproductive Work Behavior," Int. J. Sel. Assess., vol. 11, no. 1, pp. 30-42, 2003.

[15] M. Alias and R. M. Rasdi, "Organizational Predictors of Workplace Deviance among Support Staff," Procedia - Soc. Behav. Sci., vol. 172, pp. 126-133, 2015.

[16] W. J. Everton, J. a. Jolton, and P. M. Mastrangelo, "Be nice and fair or else: 
understanding reasons for employees' deviant behaviors," J. Manag. Dev., vol. 26, no. 2, pp. 117-131, 2007.

[17] S. H. Appelbaum, K. J. Deguire, and M. Lay, "The relationship of ethical climate to deviant workplace behaviour," Corp. Gov., vol. 5, no. 4, pp. 43-55, 2005.

[18] S. H. Appelbaum, G. D. Iaconi, and A. Matousek, "Positive and negative deviant workplace behaviors: causes, impacts, and solutions," Corp. Gov., vol. 7, no. 5, pp. 586598, 2007.

[19] S. Chiu and S. Yeh, "Role stressors and employee deviance: the moderating effect of social support," Pers. Rev., vol. 44, no. 2, pp. 308-324, 2015.

[20] N. Dimotakis, R. Ilies, and M. K. Mount, "Intentional negative behaviors at work," in Research in personnel and human resources management, J. Martocchio, H. Liao, and A. Joshi, Eds. Amsterdam, the Netherlands: Elsevier., 2008, pp. 247-277.

[21] C. A. Henle, "Predicting Workplace Deviance from the Interaction between Organizational Justice and Personality," J. Manag. Issues, vol. 17, no. 2, pp. 247-263, 2005.

[22] C. Smithikrai, "Relationship of cultural values to counterproductive work behaviour: The mediating role of job stress," Asian J. Soc. Psychol., vol. 17, pp. 36-43, 2014.

[23] K. Chang and C. Smithikrai, "Counterproductive behaviour at work: an investigation into reduction strategies," Int. J. Hum. Resour. Manag., vol. 21, no. December, pp. 1272-1288, 2010.

[24] R. J. Bennett and S. L. Robinson, "Development of a measure of workplace deviance.," J. Appl. Psychol., vol. 85, no. 3, pp. 349-360, 2000.
[25] C. M. Berry, D. S. Ones, and P. R. Sackett, "Interpersonal deviance, organizational deviance, and their common correlates: a review and meta-analysis.," J. Appl. Psychol., vol. 92, no. 2, pp. 410-424, 2007.

[26] L. C. Lim, C. Y. F. Benjamin, and C. J. Teh, "Perceived Organizational Support and Workplace Deviance in the Voluntary Sector," Procedia Econ. Financ., vol. 35, no. October 2015, pp. 468-475, 2016.

[27] L. Miller, "Workplace Violence: Prevention, Response, and Recovery," Psychotherapy, vol. 36, no. 2, pp. 160-169, 1999.

[28] L. Miller, "Tough Guys: Psychotherapeutic strategies with law enforcement and emergency services personnel," Psychotherapy, vol. 32, no. 4, pp. 592-600, 1995.

[29] S. Mitani, M. Fujita, K. Nakata, and T. Shirakawa, "Impact of post-traumatic stress disorder and job-related stress on burnout: a study of fire service workers," J. Emerg. Med., vol. 31, no. 1, pp. 7-11, 2006.

[30] M. Nasir and A. Bashir, "Examining workplace deviance in public sector organizations of Pakistan," Int. J. Soc. Econ., vol. 39, pp. 240-253, 2012.

[31] P. E. Spector, S. Fox, L. M. Penney, K. Bruursema, A. Goh, and S. Kessler, "The dimensionality of counterproductivity: Are all counterproductive behaviors created equal?," J. Vocat. Behav., vol. 68, pp. 446-460, 2006.

[32] N. A. Bowling and M. L. Gruys, "Human Resource Management Review Overlooked issues in the conceptualization and measurement of counterproductive work behavior," Hum. Resour. Manag. Rev., vol. 20, no. 1, pp. 54-61, 2010. 